\title{
Effects of dietary guidance on the symptoms, quality of life and habitual dietary intake of patients with irritable bowel syndrome
}

\author{
TAREK MAZZAWI $^{1,2}$, TRYGVE HAUSKEN ${ }^{2}$, DORIS GUNDERSEN $^{3}$ and MAGDY EL-SALHY ${ }^{1,2}$ \\ ${ }^{1}$ Section for Gastroenterology, Department of Medicine, Stord Helse-Fonna Hospital, Stord; \\ ${ }^{2}$ Section for Gastroenterology, Institute of Medicine, Bergen University, Bergen; \\ ${ }^{3}$ Department of Research, Helse-Fonna, Haugesund, Norway
}

Received January 13, 2013; Accepted June 17, 2013

DOI: $10.3892 / \mathrm{mmr} .2013 .1565$

\begin{abstract}
Diet is important in triggering the symptoms of irritable bowel syndrome (IBS). This study investigated the impact of dietary guidance on the symptoms, quality of life and habitual diet of patients with IBS. Forty-six patients who fulfilled the Rome III criteria for the diagnosis of IBS were included. Of these patients, 17 completed the entire study. Each patient attended three sessions ( $\sim 5 \mathrm{~min}$ in duration) and received individual guidance on their dietary management. The patients were asked to complete the following questionnaires prior to receiving the dietary guidance, and at least 3 months subsequently: The Birmingham IBS symptom score questionnaire, the IBS Quality of Life (IBS-QOL) questionnaire, the Short-Form Nepean and Dyspepsia Index (SF-NDI) and the MoBa Food Frequency Questionnaire (MoBa FFQ). The time at which patients completed the questionnaires following dietary guidance ranged from 3-9 months (median, 4 months). The total IBS symptom scores were reduced once the patients had received dietary guidance $(\mathrm{P}=0.001)$. The total score for the quality of life, as assessed by the IBS-QOL and the SF-NDI, increased significantly following the dietary guidance sessions $(\mathrm{P}=0.003$ and $\mathrm{P}=0.002$, respectively). There were no statistical differences in the intake of calories, carbohydrate, fiber, protein, fat or alcohol in the patients with IBS following dietary guidance. There were increases in the consumption of dairy products, $\beta$-carotene, retinol equivalents, riboflavin, vitamin $B_{12}$ and calcium, although only the increase in vitamin $B_{12}$ consumption was statistically significant. There was a significant reduction in the consumption of certain fruits and vegetables that were rich in highly fermentable short-chain carbohydrates, disaccharides, monosaccharides and polyols, as well as insoluble fibers. In conclusion, three 45-min dietary guidance sessions, administered by a nurse, reduced the symp-
\end{abstract}

Correspondence to: Professor Magdy El-Salhy, Section for Gastroenterology, Department of Medicine, Stord Helse-Fonna Hospital, Tysevegen 64, Box 4000, Stord 5409, Norway

E-mail: magdy.elsalhy@helse-fonna.no

Key words: diet, diet management, irritable bowel syndrome, quality of life toms and improved the quality of life of patients with IBS, and resulted in an adequate intake of vitamins and minerals. Individual dietary guidance is a cost-effective option for the management of IBS.

\section{Introduction}

Irritable bowel syndrome (IBS) is a chronic functional bowel disorder characterized by a combination of symptoms that have a considerable impact on the patient's quality of life. These symptoms include abdominal pain or discomfort and altered bowel habits $(1,2)$. IBS is more common in females than in males, and is diagnosed more frequently in patients under the age of 50 (1). The prevalence of IBS has been calculated to range from $5-15 \%$ of the population worldwide, as determined by diagnostic criteria, such as the Rome criteria (1-14).

Approximately two-thirds of patients with IBS consider their symptoms to be related to their diet (15) and therefore restrict their intake of certain dietary agents that they perceive to be provocative. The most commonly reported triggers are carbohydrates and fatty foods, milk and dairy products, wheat products, caffeine, hot spices, certain meats, cabbage, onions, peas, beans and fried and smoked foods (16-19). Despite these reported effects, numerous studies have demonstrated that dietary composition does not markedly differ between patients with IBS and controls (15-21), although patients with IBS appear to have a low intake of calcium, potassium, magnesium, vitamin $A$, vitamin $B_{12}$ and riboflavin $(16,18,20,21)$.

In a previous study by our group, dietary guidance administered individually to patients with IBS reduced the symptoms of the condition and improved their quality of life, in addition to affecting their habitual diet so that their intake of minerals and vitamins became normalized (18). However, two groups of patients with IBS were compared in the study; one group received individual dietary guidance, whilst the second did not receive any dietary guidance. There were several important factors in the investigation that may have affected the outcome of the study, but were not able to be excluded, such as the differences in gender distribution and social background between the two groups. The present investigation was designed to control for these factors, and studied the effects in the same individuals before and 3-9 months after receiving individual dietary guidance. 


\section{Material and methods}

Patients. Patients who had been referred to the gastroenterology department of Stord Helse-Fonna Hospital (Stord, Norway), and who fulfilled the Rome III criteria for the diagnosis of IBS were considered for inclusion in the study. Although both genders were able to participate, the patients were required to be between 18 and 69 years of age. Exclusion criteria comprised the presence of organic gastrointestinal disease, clinically significant systemic diseases, pregnancy or lactation, drug abuse, serious psychiatric diseases and collaboration issues. In addition, with the exception of appendectomy, cesarean section and hysterectomy, patients who had undergone abdominal surgery were excluded. This study was performed in accordance with the Declaration of Helsinki and was approved by the Regional Committee for Medical and Health Research Ethics West, Bergen, Norway. All patients provided oral and written consent to participate.

Study design. In total, 46 patients were included in the study. This included 35 females and 11 males with a mean age of 35 years (range, 18-69 years). Of these, 21 reported diarrhea (IBS-D), 18 reported constipation (IBS-C) and seven reported a mixture of both symptoms (IBS-M) as the predominant symptom of IBS. The patients underwent a complete physical examination, a gastroscopy with duodenal biopsies, a colonoscopy with segmental biopsies and several blood tests to exclude other organic causes for their symptoms. Each patient received three sessions of individual guidance on dietary management from a registered nurse with a specific education in IBS diet, with each session lasting $~ 45 \mathrm{~min}$. The patients were asked to complete the following questionnaires before and $\geq 3$ months subsequent to receiving the dietary guidance: The Birmingham IBS symptom score questionnaire, the IBS-Quality of Life (IBS-QOL) questionnaire, the Norwegian version of the Short-Form Nepean and Dyspepsia Index (SF-NDI) questionnaire and the MoBa Food Frequency Questionnaire (MoBa FFQ).

Individual guidance on diet management. Each patient attended three $45 \mathrm{~min}$ sessions with a registered nurse with special training in the IBS diet, and seven years experience of providing dietary guidance to patients with IBS. The sessions were scheduled with intervals of $\geq 2$ weeks between them. The information at the sessions was provided orally, and using charts and illustrative drawings. Written information was also supplied.

In the first session, the patient received general information with regard to the importance of regular meals and healthy eating habits, along with the effect of the diet on the development of symptoms. Emphasis was placed on the role of poorly absorbed, highly fermentable oligosaccharides, disaccharides, monosaccharides and polyols (FODMAPs), although patients were also informed of the effects of soluble and insoluble dietary fibers. It was emphasized that milk and dairy products were not triggers for IBS symptoms, and that the patients should consume dairy products daily. The patient was asked to keep a diary in which they recorded the time of eating/drinking, and the types of food and drinks they ingested daily. In addition, they were asked to report the occurrence of abdominal pain, abdominal distention and bloating, as well as stool frequency and consistency. The patients were instructed to try protein-, fat-, and carbohydrate-rich/poor diets and report the symptoms for each in the diary. This was performed over a 2-week period.

In the second scheduled session, the information provided in the first session was summarized, before the diary was examined to determine which food items may be triggering the patient's symptoms. The patients were then advised to avoid these items and other items that were rich in FODMAPs and insoluble fibers, such as onions, garlic, paprika, cabbage, carbonated beverages, 'lite' products (those containing artificial sweeteners), bananas, beans and peas. The patient was asked to replace wheat and wheat products with spelt and spelt products, respectively, and was provided with a list of vegetables and fruits that contained lower levels of FODMAPs and insoluble fibers (18). The patients were also instructed to avoid the intake of food items supplemented with probiotics during the course of the study.

During the third and final session, the patient's experience regarding the management of their diet was discussed with the nurse, so that the patient and nurse were then able to utilize this information to design a suitable diet for the patient to follow.

IBS symptom assessment. The Birmingham IBS symptom score questionnaire was developed to measure the symptoms of patients with IBS. It is disease-specific, acceptable to patients and suitable for self-completion. Its dimensions have been demonstrated to have good reliability, external validity and sensitivity (22). The Birmingham IBS symptom score questionnaire consists of 11 questions based on the frequency of IBS symptoms. The responses to the questions are measured on a six-point Likert scale, ranging from 0 (none of the time) to 5 (all of the time). The questionnaire has three underlying dimensions: pain (three items), diarrhea (five items) and constipation (three items), with lower scores indicating improved symptoms.

Assessment of quality of life. The quality of life in patients with IBS was assessed by the IBS-QOL and SF-NDI questionnaires.

The IBS-QOL questionnaire is a 34-item, IBS-specific quality of life measure that assesses physical and psychosocial functioning as a result of IBS $(23,24)$. The questionnaire comprises eight domains; dysphoria, interference with activity, body image, health concerns, food avoidance, social reaction, sexual function and impact on relations. Responses are provided on the following five-point Likert scale: not at all, slightly, moderately, quite a lot and extremely.

The SF-NDI questionnaire is a disease-specific measure of the health-related quality of life (HRQoL), with 10 questions divided into five subscale scores (tension, interference with daily activities, disruption to regular eating/drinking, knowledge towards/control over disease symptoms and interference with work/study). Each question has five options, ranging from 1 (not at all) to 5 (extremely); thus, the total score ranges from 10-50, as per the developer's original calculation formula, with higher scores indicating worse functioning or symptoms. This questionnaire was constructed and validated primarily in patients with dyspepsia (25). A Norwegian translation of the 
Table I. Scores on the eight domains of the Irritable Bowel Syndrome-Quality of Life (IBS-QOL) questionnaire in patients with IBS before and following dietary guidance sessions.

IBS-QOL score

\begin{tabular}{lccc} 
& Before dietary guidance & Following dietary guidance & P-value \\
\hline Dysphoria & $28.1 \pm 1.4$ & $31.5 \pm 0.9$ & $0.009^{\mathrm{b}}$ \\
Interference with activity & $18.6 \pm 0.7$ & $20.9 \pm 0.7$ & $0.003^{\mathrm{b}}$ \\
Body image & $18.1 \pm 0.8$ & $20.0 \pm 1.1$ & $0.007^{\mathrm{b}}$ \\
Health worry & $15.2 \pm 0.7$ & $16.9 \pm 0.6$ & $0.001^{\mathrm{b}}$ \\
Food avoidance & $5.8 \pm 0.6$ & $4.6 \pm 0.4$ & $0.018^{\mathrm{b}}$ \\
Social reactions & $18.8 \pm 0.8$ & $20.6 \pm 0.7$ & $0.021^{\mathrm{a}}$ \\
Sexual function & $8.2 \pm 0.4$ & $8.9 \pm 0.3$ & $0.035^{\mathrm{a}}$ \\
Impact on relations & $12.8 \pm 0.4$ & $13.4 \pm 0.4$ & 0.172
\end{tabular}

Data are presented as the mean \pm SEM. ${ }^{a} \mathrm{P}<0.05$ and ${ }^{\mathrm{b}} \mathrm{P}<0.01$.

A

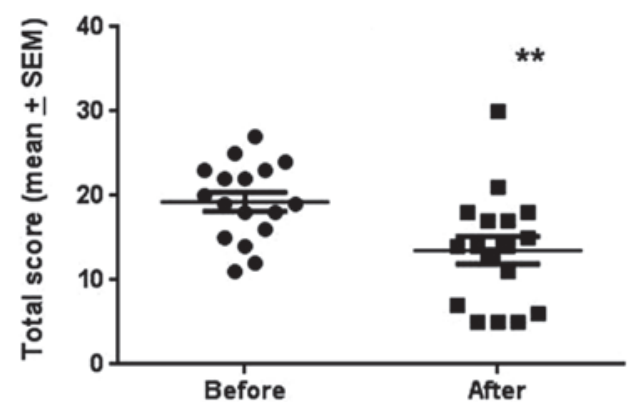

$\mathrm{C}$

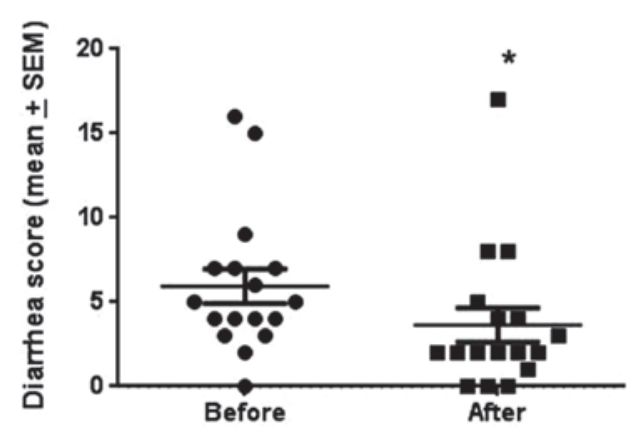

B

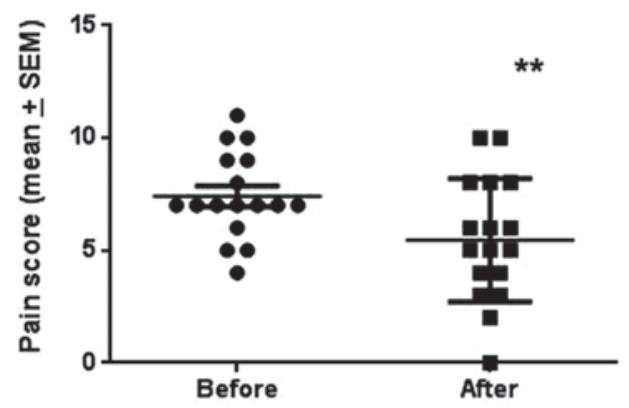

D

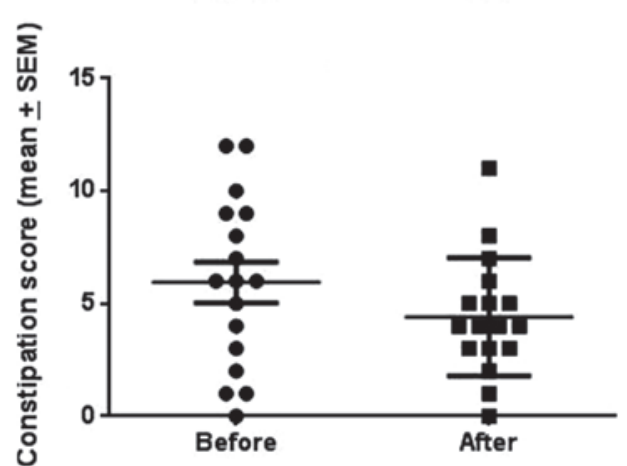

Figure 1. (A) Total score and scores on the three dimensions [(B) abdominal pain, (C) diarrhea and (D) constipation] of the Birmingham irritable bowel syndrome (IBS) symptom score questionnaire in patients with IBS before and following dietary guidance sessions. ${ }^{*} \mathrm{P}<0.05$ and ${ }^{* *} \mathrm{P}<0.01$.

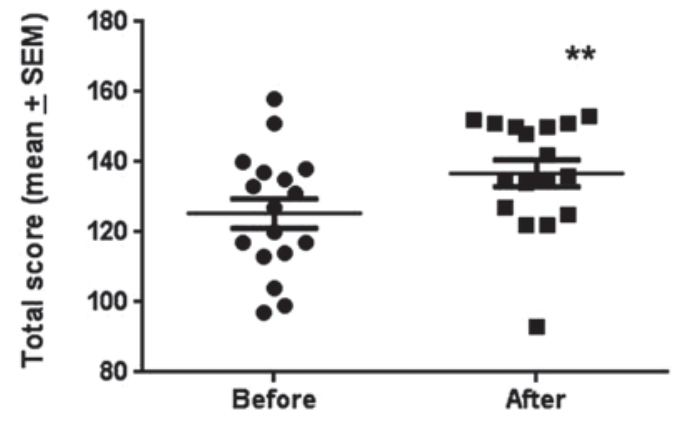

Figure 2. Total score for quality of life in patients with irritable bowel syndrome (IBS) before and following dietary guidance sessions, as assessed by the Irritable Bowel Syndrome-Quality of Life (IBS-QOL) questionnaire. ${ }^{* *} \mathrm{P}<0.01$.

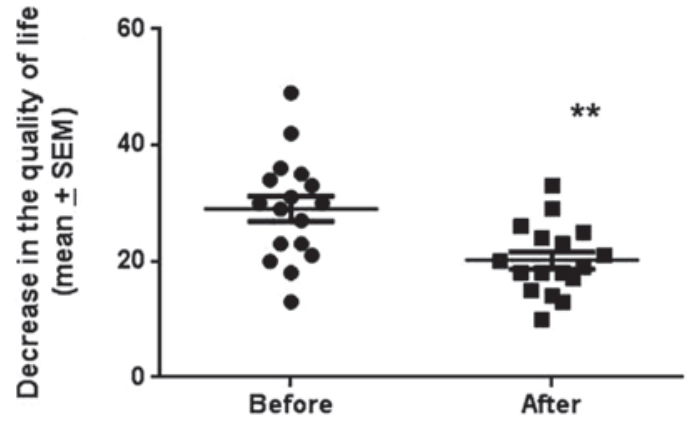

Figure 3. Total score for the reduction in quality of life, as detected by the Short-Form Nepean and Dyspepsia Index (SF-NDI) quality of life questionnaire. ${ }^{* *} \mathrm{P}<0.01$ 
Table II. Daily intake of macronutrients and alcohol in patients with irritable bowel syndrome (IBS) before and following dietary guidance sessions.

\begin{tabular}{|c|c|c|c|}
\hline & Before dietary guidance & Following dietary guidance & P-value \\
\hline Energy (kcal) & $1968 \pm 183$ & $1889 \pm 219$ & 0.610 \\
\hline \multicolumn{4}{|l|}{ Carbohydrates (g) } \\
\hline Total & $249.7 \pm 28.6$ & $228.3 \pm 30.0$ & 0.342 \\
\hline Starch & $125.8 \pm 15.5$ & $108.2 \pm 13.1$ & 0.185 \\
\hline Fiber $(\mathrm{g})$ & $27.4 \pm 2.5$ & $23.1 \pm 2.2$ & 0.093 \\
\hline Protein $(\mathrm{g})$ & $75.7 \pm 5.5$ & $78.2 \pm 9.4$ & 0.704 \\
\hline \multicolumn{4}{|l|}{ Fats (g) } \\
\hline Total & $72.5 \pm 6.3$ & $72.3 \pm 7.6$ & 0.967 \\
\hline Saturated & $26.6 \pm 2.6$ & $26.5 \pm 3.2$ & 0.965 \\
\hline Cholesterol & $232.6 \pm 26.0$ & $288.6 \pm 38.9$ & $0.040^{\mathrm{a}}$ \\
\hline Trans & $1.4 \pm 0.2$ & $1.8 \pm 0.4$ & 0.243 \\
\hline Monounsaturated & $24.2 \pm 2.1$ & $24.4 \pm 2.4$ & 0.918 \\
\hline Polyunsaturated & $14.9 \pm 1.4$ & $13.9 \pm 1.3$ & 0.334 \\
\hline Sugar (g) & $50.4 \pm 8.3$ & $49.4 \pm 9.2$ & 0.876 \\
\hline Alcohol (ml) & $1.4 \pm 0.6$ & $1.2 \pm 0.4$ & 0.620 \\
\hline
\end{tabular}

Data are presented as the mean \pm SEM. ${ }^{\mathrm{a}} \mathrm{P}<0.05$.

Table III. Weekly pattern of meal types in patients with irritable bowel syndrome (IBS) before and following dietary guidance sessions.

\begin{tabular}{lccr}
\hline & \multicolumn{2}{c}{ Number of meals } \\
\cline { 2 - 3 } Meal type & Before dietary guidance & Following dietary guidance & P-value \\
\hline Breakfast & $2.1 \pm 0.5$ & $1.8 \pm 0.4$ & 0.260 \\
Morning snack & $5.4 \pm 0.6$ & $4.4 \pm 0.5$ & 0.256 \\
Lunch & $3.9 \pm 0.6$ & $3.0 \pm 0.5$ & 0.219 \\
Snack before dinner & $6.2 \pm 0.6$ & $5.9 \pm 0.6$ & 0.716 \\
Dinner & $1.4 \pm 0.2$ & $1.3 \pm 0.2$ & 0.579 \\
Evening snack & $5.6 \pm 0.6$ & $6.2 \pm 0.5$ & 0.370 \\
Supper & $3.1 \pm 0.5$ & $3.2 \pm 0.4$ & 0.675 \\
Night time meal & $7.4 \pm 0.5$ & $7.2 \pm 0.5$ & 0.867 \\
\hline
\end{tabular}

Data are presented as the mean \pm SEM.

questionnaire was validated and demonstrated to perform well in patients with IBS (26).

Dietary assessment. Dietary intake was assessed using a semi-quantitative, self-administered food frequency questionnaire (MoBa FFQ). The MoBa FFQ asks participants to report the frequency of consumption and portion size of certain items over a defined period of time. Each item is defined by a series of foods or beverages. Additional questions on food purchasing and preparation methods enable the analysis software to further refine nutrient calculations. The MoBa FFQ used in this study was developed and validated by the Norwegian Institute of Public Health in Oslo, Norway $(27,28)$. It enquires about the intake of 225 food items, grouped according to typical Norwegian meal patterns, and is designed to capture the dietary habits of the participant over a defined period, including the intake of any oral supplements. Analysis of the obtained data provides information concerning the intake of energy, water, macronutrients, micronutrients, minerals and alcohol, in addition to 100 specific food groups and items. It also yields information regarding meal patterns.

Statistical analysis. The paired t-test was used to analyze the data. The data are presented as the mean \pm SEM values, and $\mathrm{P}<0.05$ was considered to indicate a statistically significant difference. 
Table IV. Daily intake of dairy products, artificial sweeteners and soft drinks in patients with irritable bowel syndrome (IBS) before and following dietary guidance sessions.

\begin{tabular}{|c|c|c|c|}
\hline Dairy products & Before dietary guidance & Following dietary guidance & P-value \\
\hline Milk products, whole fat (g) & $0.8 \pm 0.5$ & $6.2 \pm 5.0$ & 0.262 \\
\hline Milk products, low fat (g) & $118.8 \pm 59.9$ & $138.7 \pm 82.8$ & 0.506 \\
\hline Sour milk with probiotic supplement (g) & $31.5 \pm 29.3$ & $4.5 \pm 2.6$ & 0.339 \\
\hline Yoghurt (g) & $14.1 \pm 4.6$ & $34.4 \pm 10.6$ & 0.070 \\
\hline Soya milk (g) & $0.9 \pm 0.6$ & $1.3 \pm 0.9$ & 0.332 \\
\hline Cheese, whole fat (g) & $7.0 \pm 2.9$ & $7.8 \pm 3.7$ & 0.676 \\
\hline Cheese, low fat (g) & $0.2 \pm 0.1$ & $0.4 \pm 0.2$ & 0.260 \\
\hline Brown goat's cheese (g) & $1.1 \pm 0.4$ & $2.6 \pm 1.8$ & 0.335 \\
\hline Artificial sweeteners (mg) & $0.02 \pm 0.01$ & $0.01 \pm 0.01$ & 0.163 \\
\hline Soft drinks, sweetened (ml) & $71.3 \pm 31.9$ & $53.5 \pm 20.7$ & 0.478 \\
\hline Soft drinks, unsweetened (ml) & $91.7 \pm 39.8$ & $37.5 \pm 29.2$ & 0.085 \\
\hline
\end{tabular}

Data are presented as the mean \pm SEM.

Table V. Daily intake of vitamins and minerals in patients with irritable bowel syndrome (IBS) before and following dietary guidance sessions.

\begin{tabular}{|c|c|c|c|}
\hline & Before dietary guidance & Following dietary guidance & P-value \\
\hline \multicolumn{4}{|l|}{ Vitamins } \\
\hline$\beta$-carotene (mg) & $2543 \pm 511$ & $2721 \pm 360$ & 0.624 \\
\hline Folate $(\mu \mathrm{g})$ & $224.8 \pm 17.8$ & $223.2 \pm 28.8$ & 0.942 \\
\hline Niacin equivalents $(\mu \mathrm{g})$ & $28.3 \pm 2.0$ & $29.5 \pm 3.1$ & 0.584 \\
\hline Retinol equivalents (mg) & $839 \pm 95$ & $1039 \pm 152$ & 0.199 \\
\hline Riboflavin (mg) & $1.5 \pm 0.2$ & $1.7 \pm 0.3$ & 0.513 \\
\hline Thiamin (mg) & $1.3 \pm 0.1$ & $1.2 \pm 0.2$ & 0.727 \\
\hline Vitamin $\mathrm{B}_{6}(\mathrm{mg})$ & $1.4 \pm 0.1$ & $1.3 \pm 0.1$ & 0.478 \\
\hline Vitamin $\mathrm{B}_{12}(\mu \mathrm{g})$ & $4.5 \pm 0.5$ & $6.1 \pm 1.1$ & $0.042^{\mathrm{a}}$ \\
\hline Vitamin C (mg) & $124.6 \pm 18.3$ & $126.1 \pm 16.6$ & 0.913 \\
\hline Vitamin $\mathrm{D}(\mu \mathrm{g})$ & $2.9 \pm 0.4$ & $3.8 \pm 0.5$ & 0.079 \\
\hline Vitamin E (mg) & $10.2 \pm 0.9$ & $10.1 \pm 0.9$ & 0.941 \\
\hline \multicolumn{4}{|l|}{ Minerals } \\
\hline Calcium (mg) & $773 \pm 85$ & $884 \pm 186$ & 0.373 \\
\hline Copper (mg) & $1.2 \pm 0.1$ & $1.1 \pm 0.1$ & 0.383 \\
\hline Iron (mg) & $9.7 \pm 0.7$ & $8.9 \pm 0.9$ & 0.412 \\
\hline Magnesium (mg) & $358 \pm 28.3$ & $333.5 \pm 42.8$ & 0.500 \\
\hline Phosphorus (mg) & $1455 \pm 110$ & $1475 \pm 213$ & 0.901 \\
\hline Potassium (mg) & $3577 \pm 281$ & $3454 \pm 400$ & 0.686 \\
\hline Selenium $(\mu \mathrm{g})$ & $50.1 \pm 3.7$ & $54.6 \pm 5.9$ & 0.316 \\
\hline Sodium (mg) & $2694 \pm 209$ & $2618 \pm 276$ & 0.754 \\
\hline Zinc (mg) & $9.6 \pm 0.7$ & $9.5 \pm 1.2$ & 0.925 \\
\hline
\end{tabular}

Data are presented as the mean \pm SEM. ${ }^{\mathrm{a}} \mathrm{P}<0.05$.

\section{Results}

Patients. Of the 46 patients recruited to this study, 18 abandoned the study; one was excluded due to non-compliance and one due to cooperation problems; four became better following the dietary guidance sessions, and then lost interest in and motivation for completing the study; two were diagnosed with celiac disease; one was diagnosed with lupus; one became pregnant and one moved abroad during the study. Thus, 17 of the original 46 patient cohort completed the study. These 
Table VI. Daily intake of various vegetables, fruits and berries in patients with irritable bowel syndrome (IBS) before and following dietary guidance sessions.

Daily intake (g)

\begin{tabular}{|c|c|c|c|}
\hline Vegetables/fruits/berries & Before dietary guidance & Following dietary guidance & P-value \\
\hline Cauliflower: raw & $1.4 \pm 0.9$ & $0.7 \pm 0.6$ & 0.300 \\
\hline Cauliflower: cooked & $4.9 \pm 2.0$ & $4.9 \pm 2.8$ & 0.996 \\
\hline Broccoli: raw & $1.5 \pm 1.0$ & $1.2 \pm 1.0$ & 0.821 \\
\hline Broccoli: cooked & $5.2 \pm 1.4$ & $5.4 \pm 2.2$ & 0.909 \\
\hline Peas & $2.1 \pm 0.5$ & $0.4 \pm 0.2$ & $0.006^{\mathrm{b}}$ \\
\hline Cabbage: raw & $1.5 \pm 1.0$ & $0.1 \pm 0.1$ & 0.193 \\
\hline Cabbage: cooked & $2.3 \pm 0.7$ & $0.2 \pm 0.2$ & $0.010^{\mathrm{a}}$ \\
\hline Paprika: raw & $4.9 \pm 1.4$ & $1.8 \pm 1.3$ & $0.006^{\mathrm{b}}$ \\
\hline Paprika: cooked & $3.3 \pm 0.9$ & $0.7 \pm 0.3$ & $0.019^{\mathrm{a}}$ \\
\hline Onion, leak or garlic & $11.5 \pm 2.9$ & $1.7 \pm 0.8$ & $0.003^{\mathrm{b}}$ \\
\hline Tomatoes & $5.7 \pm 1.6$ & $11.2 \pm 3.4$ & 0.102 \\
\hline Potatoes: fried & $5.5 \pm 1.2$ & $7.6 \pm 1.3$ & 0.070 \\
\hline Potatoes: cooked, mashed or gratin & $63.7 \pm 9.8$ & $61.1 \pm 8.5$ & 0.770 \\
\hline Oranges & $44.5 \pm 17.4$ & $47.5 \pm 17.2$ & 0.884 \\
\hline Bananas & $24.1 \pm 8.0$ & $4.7 \pm 1.6$ & $0.023^{\mathrm{a}}$ \\
\hline Grapes & $16.2 \pm 5.0$ & $2.6 \pm 1.4$ & $0.016^{\mathrm{a}}$ \\
\hline Pears & $16.5 \pm 6.3$ & $4.5 \pm 2.4$ & 0.059 \\
\hline Apples & $29.3 \pm 8.0$ & $34.7 \pm 13.6$ & 0.688 \\
\hline Peaches & $8.9 \pm 3.2$ & $6.7 \pm 3.1$ & 0.553 \\
\hline Grapefruit & $1.4 \pm 0.9$ & $0.6 \pm 0.3$ & 0.421 \\
\hline Mangos & $4.3 \pm 2.1$ & $4.9 \pm 3.3$ & 0.885 \\
\hline Plums & $2.3 \pm 0.9$ & $4.4 \pm 2.9$ & 0.497 \\
\hline Melons & $4.9 \pm 1.4$ & $4.5 \pm 1.7$ & 0.692 \\
\hline Blueberries & $6.9 \pm 2.1$ & $6.5 \pm 2.1$ & 0.879 \\
\hline Strawberries & $12.2 \pm 3.0$ & $12.2 \pm 5.1$ & 0.992 \\
\hline Prunes: dried & $0.3 \pm 0.1$ & $0.7 \pm 0.3$ & 0.188 \\
\hline Apricots: dried & $0.5 \pm 0.3$ & $0.9 \pm 0.4$ & 0.329 \\
\hline Mushrooms & $1.7 \pm 0.3$ & $1.4 \pm 0.4$ & 0.513 \\
\hline Green beans & $0.3 \pm 0.2$ & $0.3 \pm 0.2$ & 1.000 \\
\hline
\end{tabular}

Data are presented as the mean $\pm \mathrm{SEM} .{ }^{\mathrm{a}} \mathrm{P}<0.05$ and ${ }^{\mathrm{b}} \mathrm{P}<0.01$.

Table VII. Daily intake of patients with irritable bowel syndrome (IBS), demonstrating the replacement of wheat products with spelt products following dietaryguidance sessions.

Daily intake (g)

\begin{tabular}{lccc}
\cline { 2 - 3 } Wheat/spelt products & Before dietary guidance & Following dietary guidance & P-value \\
\hline White bread & $3.4 \pm 1.7$ & $4.4 \pm 1.7$ & 0.636 \\
Dark bread & $85.4 \pm 27.3$ & $48.0 \pm 21.5$ & 0.319 \\
Spaghetti and other pasta & $15.1 \pm 2.0$ & $13.4 \pm 1.6$ & 0.456 \\
Waffles or pancakes & $10.1 \pm 2.0$ & $7.1 \pm 1.3$ & 0.103 \\
Chocolate cakes & $5.1 \pm 0.8$ & $2.8 \pm 0.7$ & $0.002^{\mathrm{b}}$ \\
Crisp bread & $15.4 \pm 7.2$ & $17.2 \pm 6.3$ & 0.723 \\
Sweet buns & $4.7 \pm 1.5$ & $1.1 \pm 0.3$ & $0.025^{\mathrm{a}}$
\end{tabular}

Data are presented as the mean \pm SEM. ${ }^{a} \mathrm{P}<0.05$ and ${ }^{\mathrm{b}} \mathrm{P}<0.01$. 
patients comprised 12 females and five males with a mean age of 34 years (range, 20-45 years); six of the 17 were IBS-D, eight were IBS-C and three were IBS-M. The time taken between receiving dietary guidance and completing the second set of questionnaires ranged from 3-9 months (median, 4 months).

Birmingham IBS symptom score questionnaire. The total scores of the Birmingham IBS symptom score questionnaires before and subsequent to receiving dietary guidance were $41.47 \pm 1.62$ and $35.71 \pm 1.12$, respectively. The reduction in symptoms was statistically significant $(\mathrm{P}=0.001)$. All three of the questionnaire dimensions (i.e., abdominal pain, diarrhea and constipation) were also reduced following the dietary guidance sessions; however, the result for constipation was not statistically significant (Fig. 1).

$I B S-Q O L$. The total IBS-QOL score increased significantly from $125.4 \pm 4.2$ to $136.8 \pm 3.8$ following the dietary guidance sessions $(\mathrm{P}=0.003)$. This improvement was statistically significant in all domains, with the exception of the impact on relations (Fig. 2 and Table I).

SF-NDI. The total SF-NDI scores (which reflect the reduction in HRQoL) before and following the dietary guidance sessions were $29.1 \pm 2.2$ and $20.2 \pm 1.5$, respectively. This improvement in HRQoL was statistically significant ( $\mathrm{P}=0.002$; Fig. 3).

$M o B a$ FFQ. There were no statistically significant differences in the intake of calories, carbohydrate (total and starch), fiber, protein, fat (total, saturated and trans-, mono- and polyunsaturated), sugar or alcohol in the patients with IBS who received dietary guidance (Table II). However, there was a significant increase in the intake of cholesterol. The dietary guidance did not affect the meal pattern in the patients with IBS (Table III). There was an increase in the consumption of various dairy products, although the change was not statistically significant (Table IV). However, there was a decrease in the consumption of dairy products with probiotic supplements, in line with our recommendation during the study. Although the intake of $\beta$-carotene, retinol equivalents, calcium and riboflavin was increased, only the increase in vitamin $B_{12}$ was statistically significant (Table V). There was a significant reduction in the consumption of various FODMAP- and insoluble fiber-rich fruits and vegetables (Table VI). The replacement of wheat and wheat products with spelt and spelt products, respectively, enabled the patients to consume the food items that they considered essential (Table VII).

\section{Discussion}

There was a high incompletion rate in this study, with a completion rate of only $37 \%$, and a rate of abandonment of $39 \%$. This was within the limits $(30-40 \%)$ of comparative studies $(18,29)$. The low number of patients completing the study was due to several factors; $4 \%$ due to non-compliance and collaboration problems leading to exclusion; $9 \%$ due to a marked improvement in symptoms following the dietary guidance leading to a lack of motivation to continue with the study; $7 \%$ due to the diagnosis of an organic disease during the study; and $4 \%$ due to pregnancy and moving abroad.
A previous study demonstrated that although patients with IBS purposely avoided certain food items that were rich in FODMAPs, they unknowingly maintained a high FODMAP intake due to the consumption of alternative FODMAP-rich sources (18). It has also been reported that patients with IBS avoid certain food items, such as milk and dairy products, unnecessarily, which results in a low intake of certain vitamins and minerals $(15,16,18,20)$. It is therefore apparent that patients with IBS require guidance to appropriately manage their diet.

The question of how dietary guidance should be provided, and what should it contain, remains unanswered. Individual guidance has been demonstrated to be effective in reducing the symptoms and improving the quality of life of patients with IBS (18), in comparison with guidance provided in a group situation (i.e., an IBS school), which has been demonstrated to be less effective (30-32). As discussed previously (20), the common dietary advice given to patients with IBS to reduce symptoms is unmanageable in daily life, and raises the risk of inadequate nutrient intake, particularly of vitamins and minerals. Dietary advice should be simple and easy to apply. In the present study, the patients were advised to avoid a small number of food items that were richest in FODMAPs and insoluble fibers, such as onions, garlic, paprika, beans and peas. In addition, they were advised to avoid foods containing artificial sweeteners and carbonated beverages.

In the present study, the replacement of wheat and wheat products with spelt and spelt products, respectively, enabled the patients with IBS to continue to consume food items, such as bread, without a drastic change to their lifestyle. Spelt is known to contain fewer galactans and fructans (both of which are FODMAPs) than wheat. This observation challenges the emerging concept that gluten has a role in the development of symptoms in IBS (33).

The present results demonstrate that three sessions of dietary guidance, each lasting $45 \mathrm{~min}$ and provided by a nurse, may reduce the symptoms and improve the quality of life of patients with IBS, as well improving their vitamin and mineral intake. This effect has been demonstrated to be long-term (18). This indicates that dietary guidance may be used as a cost-effective option for the management of IBS; combining dietary guidance with other lifestyle measures, such as a regular intake of probiotics and regular exercise, would augment the effect of dietary management (34). Food supplements with beneficial bacteria, including Lactobacillus spp. and Bifidobacterium spp., would increase the tolerance to both FODMAPs and fibers, since they do not produce gas on fermenting carbohydrates (1). In addition, physical activity has been found to increase gastrointestinal transit $(35,36)$.

\section{References}

1. El-Salhy M, Gundersen D, Hatlebakk JG and Hausken T (eds): Irritable bowel syndrome. Nova Science Publishers, New York, NY, 2012.

2. Thompson WG: A world view of IBS. In: Irritable Bowel Syndrome: Diagnosis and Treatment. Camilleri M and Spiller RC (eds). WB Saunders, Edinburgh, pp17-26, 2002.

3. Agréus L, Svärdsudd K, Nyrén O and Tibblin G: Irritable bowel syndrome and dyspepsia in the general population: overlap and lack of stability over time. Gastroenterology 109: 671-680, 1995.

4. Thompson WG and Heaton KW: Functional bowel disorders in apparently healthy people. Gastorenterology 79: 283-288, 1980. 
5. Kennedy TM, Jones RH, Hungin AP, O'Flanagan $\mathrm{H}$ and Kelly P: Irritable bowel syndrome, gastro-oesophageal reflux, and bronchial hyper-responsiveness in the general population. Gut 43: 770-774, 1998.

6. Drossman DA, Li Z, Andruzzi E, Temple RD, Talley NJ, Thompson WG, Whitehead WE, Janssens J, et al: U.S. householder survey of functional gastrointestinal disorders. Prevalence, sociodemography, and health impact. Dig Dis Sci 38: 1569-1580, 1993.

7. Talley NJ, Gabriel SE, Harmsen WS, Zinsmeister AR and Evans RW: Medical costs in community subjects with irritable bowel syndrome. Gastroenterology 109: 1736-1741, 1995.

8. Hungin AP, Whorwell PJ, Tack J and Mearin F: The prevalence, patterns and impact of irritable bowel syndrome: an international survey of 40,000 subjects. Aliment Pharmacol Ther 17: 643-650, 2003.

9. Jones R and Lydeard S: Irritable bowel syndrome in the general population. BMJ 304: 87-90, 1992.

10. Bordie AK: Functional disorders of the colon. J Indian Med Assoc 58: 451-456, 1972

11. O'Keefe EA, Talley NJ, Zinsmeister AR and Jacobsen SJ: Bowe disorders impair functional status and quality of life in the elderly: a population-based study. J Gerontol A Biol Sci Med Sci 50: M184-M189, 1995.

12. Everhart JE and Renault PF: Irritable bowel syndrome in office-based practice in the United States. Gastroenterology 100: 998-1005, 1991.

13. Wilson S, Roberts L, Roalfe A, Bridge P and Singh S: Prevalence of irritable bowel syndrome: a community survey. Br J Gen Pract 54: 495-502, 2004.

14. Harvey RF, Salih SY and Read AE: Organic and functional disorders in 2000 gastroenterology outpatients. Lancet 1: 632-634, 1983.

15. Simrén M, Månsson A, Langkilde AM, Svedlund J, Abrahamsson H, Bengtsson U and Björnsson ES: Food-related gastrointestinal symptoms in the irritable bowel syndrome. Digestion 63: 108-115, 2001.

16. Williams EA, Nai X and Corfe BM: Dietary intakes in people with irritable bowel syndrome. BMC Gastroenterol 11: 9, 2011.

17. Nanda R, James R, Smith H, Dudley CR and Jewell DP: Food intolerance and the irritable bowel syndrome. Gut 30: 1099-1104, 1989.

18. Ostgaard H, Hausken T, Gundersen D and El-Salhy M: Diet and effects of diet management on quality of life and symptoms in patients with irritable bowel syndrome. Mol Med Rep 5: $1382-1390,2012$

19. El-Salhy M, Ostgaard H, Gundersen D, Hatlebakk JG and Hausken T: The role of diet in the pathogenesis and management of irritable bowel syndrome (Review). Int J Mol Med 29: 723-731, 2012

20. Böhn L, Störsrud S and Simrén M: Nutrient intake in patient with irritable bowel syndrome compared with the general population. Neurogastroenterol Motil 25: 23-30,2013.

21. Ligaarden SC, Lydersen S and Farup PG: Diet in subjects with irritable bowel syndrome: a cross-sectional study in the general population. BMC Gastroenterol 12: 61, 2012.

22. Roalfe AK, Roberts LM and Wilson S: Evaluation of the Birmingham IBS symptom questionnaire. BMC Gastroenterol 8: 30, 2008.
23. Patrick DL, Drossman DA, Frederick IO, DiCesare J and Puder KL: Quality of life in persons with irritable bowel syndrome: development and validation of a new measure. Dig Dis Sci 43: 400-411, 1998.

24. Drossman DA, Patrick DL, Whitehead WE, Toner BB, Diament NE, Hu Y, Jia H and Bangdiwala SI: Further validation of the IBS-QOL: a disease-specific quality-of-life questionnaire. Am J Gastroenterol 95: 999-1007, 2000.

25. Talley NJ, Verlinden M and Jones M: Quality of life in functional dyspepsia: responsiveness of the Nepean Dyspepsia Index and development of a new 10-item short form. Aliment Pharmacol Ther 15: 207-216, 2001.

26. Arslan G, Lind R, Olafsson S, Florvaag E and Berstad A: Quality of life in patients with subjective food hypersensitivity: applicability of the 10-item short form of the Nepean Dyspepsia Index. Dig Dis Sci 49: 680-687, 2004.

27. Masson LF, McNeill G, Tomany JO, Simpson JA, Peace HS, Wei L, Grubb DA and Bolton-Smith C: Statistical approaches for assessing the relative validity of a food-frequency questionnaire: use of correlation coefficients and the kappa statistic. Public Health Nutr 6: 313-321, 2003.

28. Brantsaeter AL, Haugen M, Alexander J and Meltzer HM: Validity of a new food frequency questionnaire for pregnant women in the Norwegian Mother and Child Cohort Study (MoBa). Matern Child Nutr 4: 28-43, 2008.

29. Enck P, Klosterhalfen S and Kruis W: Determination of placebo effect in irritable bowel syndrome. Dtsch Med Wochenschr 130: 1934-1937, 2005 (In German).

30. Ringström G, Störsrud S, Lundqvist S Westman B and Simrén M: Development of an educational intervention for patients with Irritable Bowel Syndrome (IBS): a pilot study. BMC Gastroenterol 9: 10, 2009.

31. Ringström G, Störsrud S, Posserud I, Lundqvist S, Westman B and Simrén M: Structured patient education is superior to written information in the management of patients with irritable bowel syndrome: a randomized controlled study. Eur J Gastroenterol Hepatol 22: 420-428, 2010.

32. Ringström G, Störsrud S and Simrén M: A comparison of a short nurse-based and a long multidisciplinary version of structured patient education in irritable bowel syndrome. Eur J Gastroenterol Hepatol 24: 950-957, 2012.

33. Aziz I and Sanders DS: Emerging concepts: from coeliac disease to non-coeliac gluten sensitivity. Proc Nutr Soc 71: 576-580, 2012.

34. El-Salhy M, Lillebø E, Reinemo A, Salmelid L and Hausken T: Effects of a health program comprising reassurance, diet management, probiotics administration and regular exercise on symptoms and quality of life in patients with irritable bowel syndrome. Gastroenterol Insights 2: 21-26, 2010.

35. Strid H, Simrén M, Störsrud S, Stotzer PO and Sadik R: Effect of heavy exercise on gastrointestinal transit in endurance athletes. Scand J Gastroenterol 46: 673-677, 2011.

36. Huang W, Huang X, Xing Z, Qiu X, Wang Y, Fan R, Liu W, et al: Meranzin hydrate induces similar effect to Fructus Aurantii on intestinal motility through activation of $\mathrm{H} 1$ histamine receptors. J Gastrointest Surg 15: 87-96, 2011. 